\title{
Determination of Molecular Property, Bioactivity Score and Binding Energy of the Phytochemical Compounds Present in Cassia Auriculata by Molinspiration and DFT Method
}

\author{
Article by Chandra Mohan. $\mathrm{A}^{1}$, Geetha. $\mathrm{S}^{2}$, Gajalakshmi. $\mathrm{R}^{3}$, Divya. S. $\mathrm{R}^{4}$, and Dhanarajan \\ M.S $\mathrm{S}^{5}$ \\ ${ }^{1}$ Professor \\ ${ }^{2,34}$ Assitant Professor, PG and Research Department of Biochemistry and Chemistry, Jaya \\ College of Arts and Science, India \\ ${ }^{5}$ Registrar, Texila American University, Guyana, South America \\ E-mail: chandru2c813@gmail.com ${ }^{1}$
}

\begin{abstract}
Phytoconstituent present in Cassia Auriculata were found to obey the Lipinski's rule (MiLog $P<5$ ) $\alpha$-Tocopherol (2.007) indicated their drug likeness property. Among these compounds, $\alpha$-Tocopherol exhibited highest score towards GPCR ligand, (0.25) nuclear receptor ligand (0.43) and inhibitory activities towards protease (0.29), enzyme (0.25) and kinase (-0.22) inhibitors compared to others. Insilico determination of binding energy using DFT method proved that $\alpha$-Tocopherol was found to possess good binding energy (B3LYP and HF method were found to -1228.3913, -1236.9904 \&1243.4557 a.u. and $-1220.2810,-1228.4658$ \&-1234.8000 a.u.) among others hence it was found to be more stable.
\end{abstract}

Keywords: Cassia auriculata phytochemical compounds, Molinspiration software, DFT methods and Insilico prediction.

\section{Introduction}

Cassia auriculata is one of the herbaceous plants that found throughout central and southern India, also cultivated in Punjab, Haryana, Uttar Pradesh and West Bengal. The shrub usually occurs on roadsides, waste line, and railway embankments. Avaram (Cassia auriculata Linn), family Caesalpiniaceae, is also known as Avaram tree. Cassia auriculata Linn (Family: Caesalpiniaceae) commonly known as Tanners senna, is distributed throughout hot deciduous forests of India and holds a very prestigious position in Ayurveda and Siddha systems of medicine. It was profoundly used in Ayurvedic medicine as a tonic, astringent and as a remedy for diabetes, conjunctivitis and opthalmia [1]. It is one of the principle constituents of 'Avaarai panchaga chooranam'- an Indian herbal formulation used in the treatment of diabetes to control the blood sugar level [2].

The plant has been reported to possess antipyretic [3], hepatoprotective [4], antidiabetic, antiperoxidative and antihyperglyceamic [5], microbicidal [6] and antihyperlipidaemic activities [7]. The flowers are used to treat urinary discharges, nocturnal emissions, diabetes and throat irritation [8]. They are one of the constituent of polyherbal formulation 'Diasulin' in the concentration range of 40 $\mathrm{mg} / \mathrm{dl}$ which is proven to have antidiabetic activity [9].

It has been found to possess antitumor, oncogenic, and diabeto genic properties [10]. The antioxidant and radical scavenger function of $\alpha$-tocopherol is essentially dependent on the free state of its hydroxyl group. Spectacular antiallergic and antiinflamatory activities have been attributed to DL- $\alpha$ - tocopheryl$\alpha$ - D-mannopyranoside and DL- $\alpha$-tocopheryl- $\beta$-D-galactopyranoside [11]. Hexadecanoic acid methyl ester, also known as Methyl palmitate, in the methanol fraction is an aliphatic acid ester reported to cause growth inhibition and apoptosis induction in human gastric cancer cells [12].

The phytoconstituent of a plant will often determine the physiological action on the human body. Cassia species are rich sources of Polyphenols, Anthraquinone derivatives, Flavanoids, Polysaccharides, Saponins, Tannins, and Steroids. Some of the Cassia species are rich in Glycerides with linoleic, oleic, stearic, and palmitic acids .Cassia species are well known for their laxative and purgative constituents and are also used for the treatment of skin diseases. Leaves are anthelmintic and 
also used to treat ulcers, skin diseases, and leprosy. An aqueous extract of leaves possesses hypoglycemic activity. The leaves are eaten as a vegetable in times of scarcity, the infusion of leaves possesses a slight purgative activity.

\section{Molnispiration}

Molinspiration, web based software was used to obtain parameter such as MiLogP, TPSA, drug likeness scores. MiLogP is calculated by the methodology developed by Molinspiration as a sum of fragment based contributions and correction factors. MiLog P parameter is used to check good permeability across the cell membrane. Partition coefficient or $\log \mathrm{P}$ is an important parameter used in rational drug design to measure molecular hydrophobicity. Hydrophilic/lipophilic nature of drug molecule affects drug absorption, bioavailability, drug-receptor interactions, metabolism of molecules, as well as their toxicity. Molecular Polar Surface Area TPSA is calculated based as a sum of fragment contributions of $\mathrm{O}$ and $\mathrm{N}$ - centered polar fragments. Total polar surface area (TPSA) is closely related to the hydrogen bonding potential of a molecule and is a very good predictor of drug transport properties such as intestinal absorption, bioavailability, blood brain barrier penetration etc. Calculation of volume developed at Molinspiration is based on group contributors. Number of rotatable bonds measures molecular flexibility. It is a very good descriptor of absorption and bioavailbility of drugs. Through drug likeness datas of molecule, it can be checked molecular properties and structure feature in respect to known drugs.

Bioactivity of the drug can be checked by calculating the activity score of GPCR ligand, ion channel modulator, nuclear receptor legend, kinase inhibitor, protease inhibitor, enzyme inhibitor. All the parameters were checked with the help of software .Calculated drug likeness score of each compounds were compared with the specific activity of other compounds and the results were compared with standard drug. For organic molecules the probability is if the bioactivity score is $(>0)$, then it is active, if $(-5.0-0.0)$ then moderately active, if $(<-5.0)$ then inactive. The drug likeness scores were calculated by considering MiLogP (partition coefficient), molecular weight, number of heavy atoms, number of hydrogen donor, number of hydrogen acceptor and number of violation, number of rotatable bonds and volume [13-18].

\section{i) Lipinski's rule}

Lipinski's rule of five also known as the Pfizer's rule of five or simply the Rule of five (RO5) is a rule of thumb to evaluate drug likeness or determine if a chemical compound with a certain pharmacological or biological activity has properties that would make it a likely orally active drug in humans. The rule was formulated by Christopher A. Lipinski in 1997.

The rule describes molecular properties important for a drug's pharmacokinetics in the human body, including their absorption, distribution, metabolism, and excretion ("ADME") Components of the Lipinski's rule:

\section{ii) Lipinski's rule states}

- Not more than 5 hydrogen bond donors (nitrogen or oxygen atoms with one or more hydrogen atoms).

- Not more than 10 hydrogen bond acceptors (nitrogen or oxygen atoms).

- A molecular mass less than 500 daltons.

- An octanal-water partition coefficient $\log P$ not greater than 5 .

- No more than one number of violation.

\section{iii) Drug likeness score}

Molinspiration, web based software was used to obtain parameter such as MiLogP, TPSA, drug likeness. MiLogP, is calculated by the methodology developed by Molinspiration as a sum of fragment based contributions and correction factors. MiLog P parameter is used to check good permeability across the cell membrane. TPSA is related to hydrogen bonding potential of compound. Calculation of volume developed at Molinspiration is based on group contributors. Number of rotatable bonds measures molecular flexibility. It is a very good descriptor of absorption and bioavailbility of drugs. 
Through drug likeness datas of molecule, it can be checked molecular properties and structure feature in respect to known drugs.

\section{iv) Bioactivity score}

Bioactivity of the drug can be checked by calculating the activity score of GPCR ligand, ion channel modulator, nuclear receptor legend, kinase inhibitor, protease inhibitor, enzyme inhibitor. All the parameters were checked with the help of software Molinspiration drug-likeness score online (www.molinspiration.com). Calculated drug likeness score of each compounds and compared with the specific activity of each compound, and the results were compared with standard drug. For organic molecules the probability is if the bioactivity score is $(>0)$, then it is active, if (-5.0-0.0) then moderately active, if $(<-5.0)$ then inactive.

\section{DFT using gaussian}

"Density", because the central quantity being computed and manipulated is not the wave function but the electron density. "Functional" because the central operators in the theory are functional -mathematic objects that take functions as arguments and return new functions as output. The "right" functional had been proven to exist, but nobody knows what it is. "Theory", because its science. We call things theories.

A variety of computational methods thus exists to reformulate the "exact" QM equations in one way or another, and then solve those equations algorithmically on a computer. Two basic approaches are DFT and something called Hartree-Fock (HF) theory. A variety of methods have also been developed that either extend HF theory (these are usually called post-HF methods), or mix HF and DFT. Nobel prize in chemistry in 1998 was awarded to Kohn and Pople basically for developments in DFT and HF respectively.

The cytochrome P450 enzymes (CYPs) metabolize many drug compounds. They catalyze a wide variety of reactions, and potentially, a large number of different metabolites can be generated. Density functional theory (DFT) has, over the past decade, been shown to be a powerful tool to rationalize and predict the possible metabolites generated by the CYPs as well as other drug-metabolizing enzymes.

DFT is a useful tool for prediction of the site of metabolism. The use of small models of the enzymes work surprisingly well for most CYP isoforms. This is probably due to the fact that the binding of the substrates is not the major determinant. When binding of the substrate plays a significant role, the wellknown issue of determining the free energy of binding is the challenge.

\section{Materials and methods}

\section{Materials}

Then the plant was identified and authenticated by Plant Anatomy Research Centre (PARC/2017/3467). Phytochemical compounds present in Cassia Auriculata like Dodecanoic acid, Ethyl Caprylate, Glycine (trifluroacetyl) - methyl butyl ester, $\alpha$ - Tocopherol and $\mathrm{n}$ - Hexadecanoic acid as given in (Figure - 1 to 6) were selected for insilico prediction.

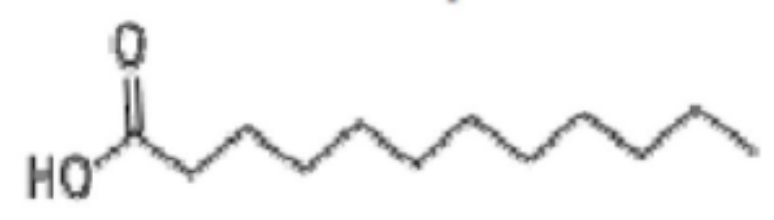

Figure 1. Dodecanoic acid 
DOI: 10.21522/TIJBMS.2016.02.02.Art002

ISSN: 2519-500X

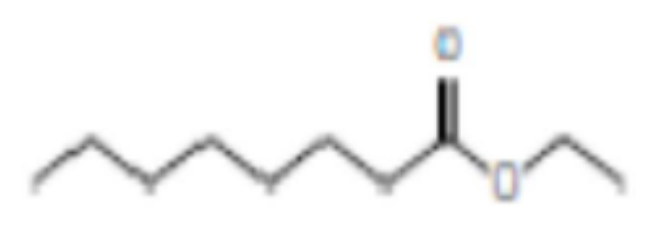

Figure 2. Ethyl caprylate

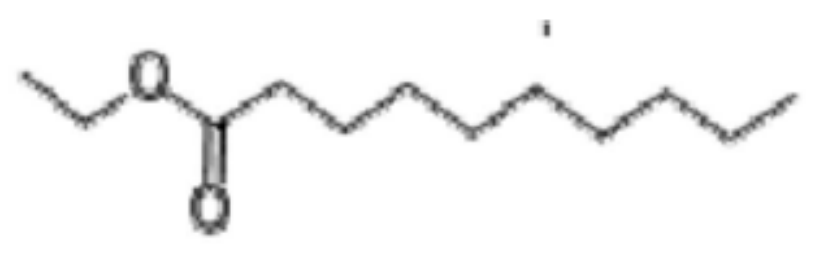

Figure 3. Capric acid ethyl ester

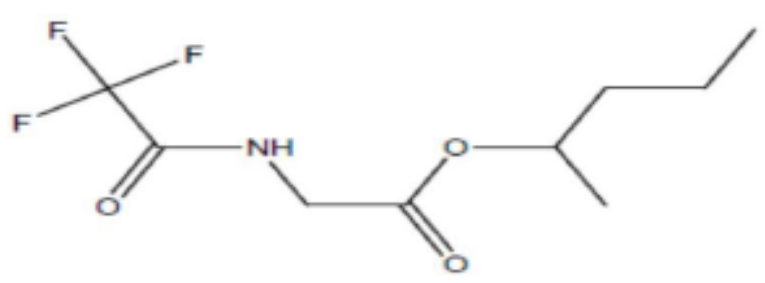

Figure 4. Glycine (trifluoroacetyl)-methyl butyl ester

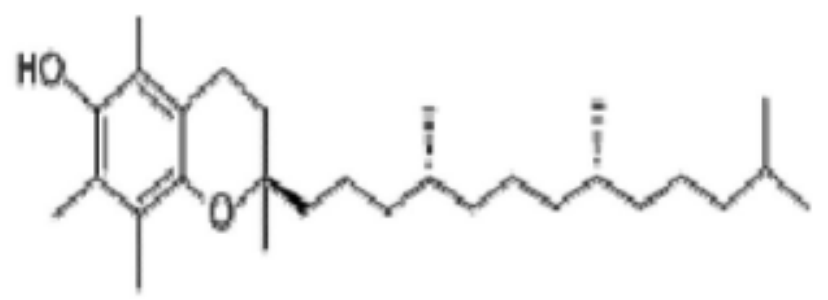

Figure 5. $\alpha$ - Tocopherol

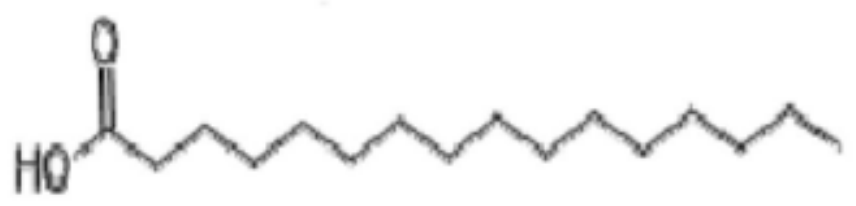

Figure 6. n-Hexadecanoic acid

\section{Methods}

\section{Molinspiration}

Structures of six phytochemical compounds selected for our work as given in Figure - 1 to $\mathbf{6}$ (reported in the literature resources) were drawn using online molinspiration for the calculation of molecular properties like MiLog P, Total polar surface area (TPSA), number of hydrogen bond donors 
Texila International Journal of Basic Medical Science Volume 2, Issue 2, Dec 2017

and acceptors, molecular weight, number of atoms, number of rotatable bonds etc., and bioactivity scores like GPCR ligands, kinase inhibitors, ion channel modulators, enzymes and nuclear receptors.

- The molecular properties and bio-activity scores predicted by molinspiration were given in Table - I a \& b. 
DOI: $10.21522 / \mathrm{TIJBMS} .2016 .02 .02 . A r t 002$

ISSN: 2519-500X

Table I (a). Molecular property of phytochemical compounds

\begin{tabular}{|c|c|c|c|c|c|c|c|c|c|c|}
\hline $\begin{array}{l}\text { S.N } \\
\text { o }\end{array}$ & $\begin{array}{l}\text { Phytochemical } \\
\text { compounds }\end{array}$ & MiLogP & TPSA & natoms & $\mathrm{nON}$ & nOHNH & $\begin{array}{l}\text { nviolatio } \\
\text { ns }\end{array}$ & nrotb & volume & MW \\
\hline 1 & Dodecanoic acid & 5.038 & 37.299 & 14.0 & 2 & 1 & 1 & 10 & 224.215 & $\begin{array}{l}200.32 \\
2\end{array}$ \\
\hline 2 & Ethyl caprylate & 3.701 & 26.305 & 12.0 & 2 & 0 & 0 & 8 & 191.338 & $\begin{array}{l}172.26 \\
8\end{array}$ \\
\hline 3 & $\begin{array}{l}\text { Glycine } \\
\text { (trifluoroacetyl)- } \\
\text { methyl butyl ester }\end{array}$ & 2.007 & 55.405 & 16.0 & 4 & 1 & 0 & 7 & 208.642 & $\begin{array}{l}241.20 \\
9\end{array}$ \\
\hline 4 & $\begin{array}{l}\text { Capric acid ethyl } \\
\text { ester }\end{array}$ & 4.711 & 26.305 & 14.0 & 2 & 0 & 0 & 10 & 224.941 & $\begin{array}{l}200.32 \\
2\end{array}$ \\
\hline 5 & $\alpha$ - Tocopherol & 8.847 & 29.462 & 30.0 & 2 & 1 & 1 & 11 & 457.697 & $\begin{array}{l}416.69 \\
0\end{array}$ \\
\hline 6 & $\begin{array}{l}\text { n- Hexadecanoic } \\
\text { acid }\end{array}$ & 7.059 & 37.299 & 18.0 & 2 & 1 & 1 & 14 & 291.422 & $\begin{array}{l}256.43 \\
0\end{array}$ \\
\hline
\end{tabular}


Table-I (b). Bioactivity score of phytochemical compounds

\begin{tabular}{|c|c|c|c|c|c|c|c|}
\hline S.No & $\begin{array}{l}\text { Phytochemical } \\
\text { compounds }\end{array}$ & $\begin{array}{l}\text { GPCR } \\
\text { ligand }\end{array}$ & $\begin{array}{l}\text { Ion Channel } \\
\text { Modulator }\end{array}$ & $\begin{array}{l}\text { Kinase } \\
\text { inhibitor }\end{array}$ & $\begin{array}{l}\text { Nuclear } \\
\text { receptor } \\
\text { ligand }\end{array}$ & $\begin{array}{l}\text { Protease } \\
\text { inhibitor }\end{array}$ & $\begin{array}{l}\text { Enzyme } \\
\text { inhibitor }\end{array}$ \\
\hline 1 & Dodecanoic acid & -0.27 & -0.04 & -0.75 & -0.24 & -0.36 & 0.04 \\
\hline 2 & Ethyl caprylate & -0.85 & -0.34 & -1.25 & -0.84 & -0.86 & -0.40 \\
\hline 3 & $\begin{array}{l}\text { Glycine } \\
\text { (trifluoroacetyl)- } \\
\text { methyl butyl ester }\end{array}$ & -0.38 & -0.38 & -0.88 & -0.31 & -0.18 & -0.12 \\
\hline 4 & $\begin{array}{l}\text { Capric acid ethyl } \\
\text { ester }\end{array}$ & -0.60 & -0.21 & -0.93 & -0.57 & -0.62 & -0.23 \\
\hline 5 & $\alpha-$ Tocopherol & 0.25 & 0.15 & -0.22 & -0.22 & 0.29 & 0.25 \\
\hline 6 & $\begin{array}{l}\text { n- Hexadecanoic } \\
\text { acid }\end{array}$ & 0.02 & 0.06 & -0.33 & -0.33 & -0.04 & 0.18 \\
\hline
\end{tabular}

$>0$ - active, $-5.0-0.0$ - moderately active, $<-5.0$ - inactive 
DOI: 10.21522/TIJBMS.2016.02.02.Art002

ISSN: $2519-500 \mathrm{X}$

- For the prediction of Molecular property, the following steps were followed

- Structures were drawn in Molinspiration by opening www.molinspiration.com

- After drawing the structure Click "Go for prediction" button, the Molecular property will appear as given in (Figure-7).

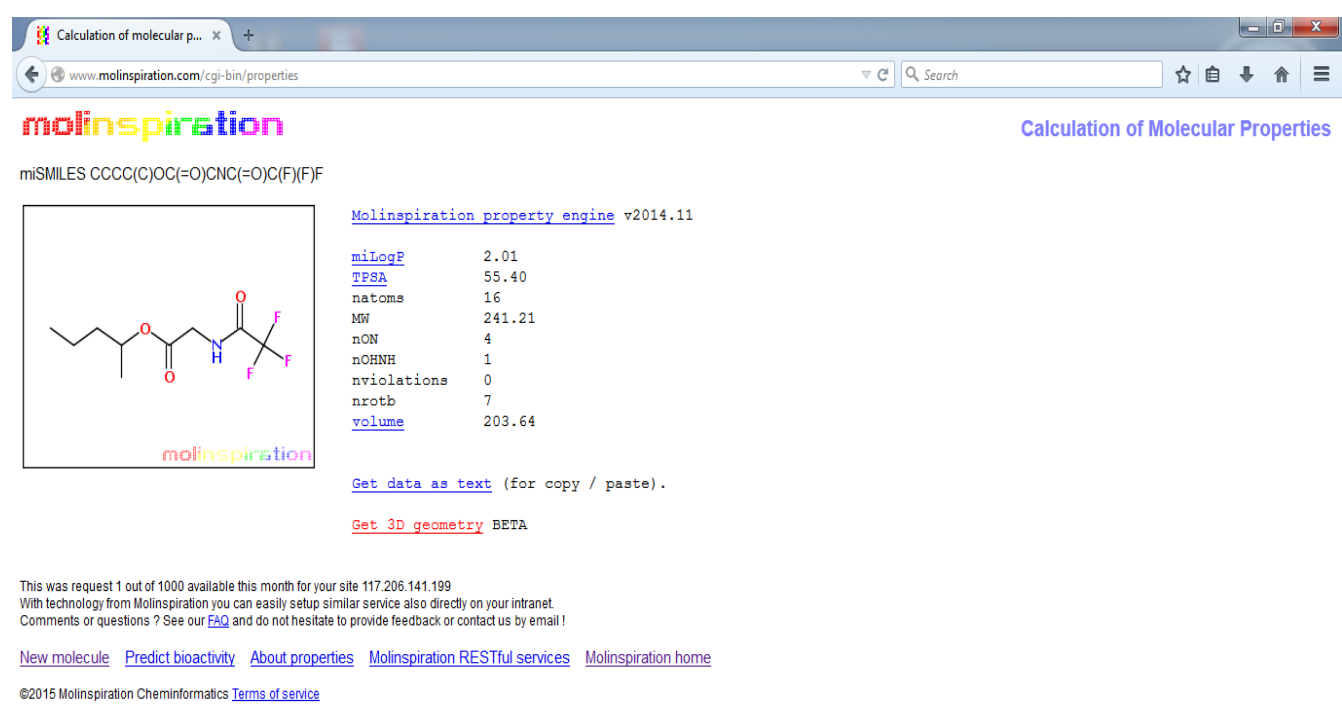

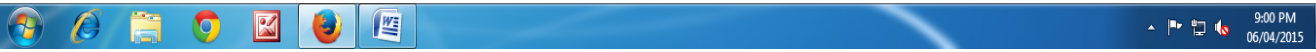

Figure 7. Molecular property setup window

- For bioactivity score prediction Click "Predict bioactivity" the window will appear as given in (Figure-8).

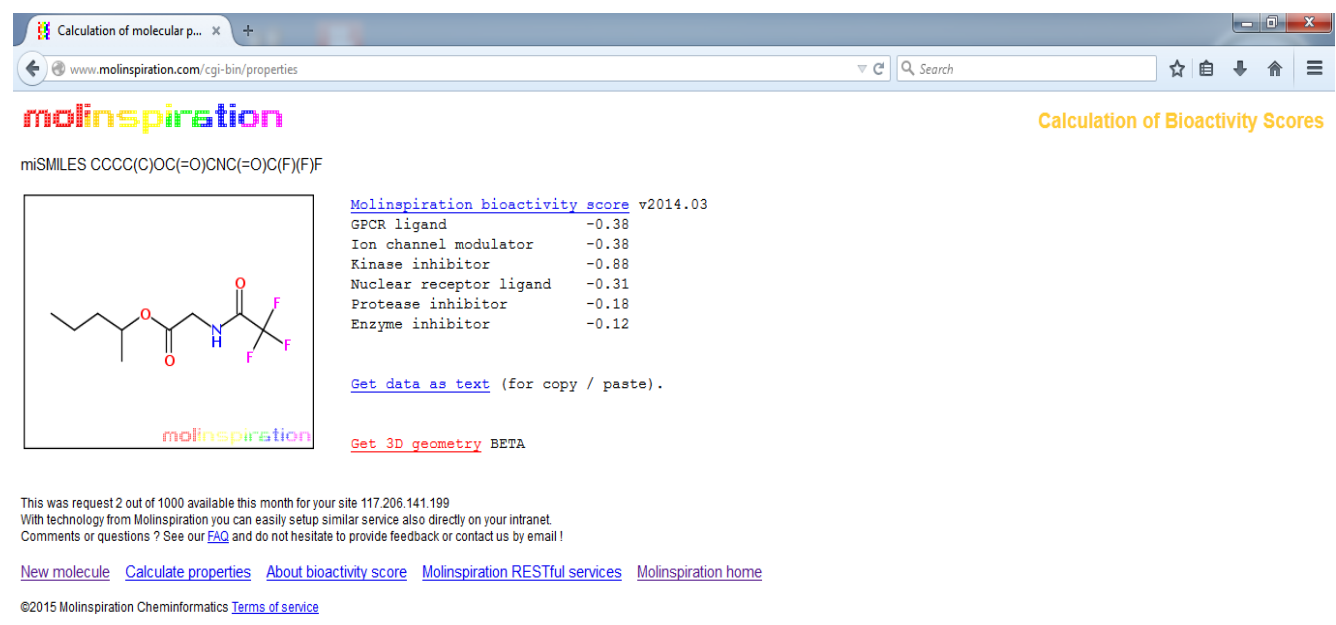

\section{(49) CA}

Figure 8. Bioactivity score setup window

\section{DFT calculation using gaussian}

DFT calculations were carried out using Gaussian software 05. Binding energies of the phytochemical constituent present in Cassia auriculata leaves like Dodecanoic acid, Ethyl caprylate, Glycine (trifluoroacetyl)-methyl butyl ester, Capric acid ethyl ester, $\alpha-$ Tocopherol and n- 
Hexadecanoic acid were calculated by B3LYP and HF methods using STO-3G, 3-21G, 6-31G basis sets [18-19].

In order to predict the binding energy of the phytoconstituents the following steps were carried out.

\section{To draw the structure}

\section{a) Using Gauss View 5.0}

i) To draw the structure of the compounds various steps involved in drawing the chemical structure were

- Open the Gauss view software

- To start a new blank workspace, go to File New Create molecule group

- Go to "View" and L-click the "builder" option "builder" window will open.

- After adding all desired atoms (excluding hydrogens) start the bonding by using the "Modify Bond" option in the "Builder". The two chosen atoms change color and are marked as 1 and 2. In addition, a new window "Semichem Smart Slide" will open press the "OK" push button after choosing the bond.

- Add hydrogen atoms by using the "Add valence" option on the "Builder" window.

- Remove atoms from the structure by using the "Delete Atom" icon on the "Builder" window.

- To save the structure, in Gaussian input file, File save as in "Gaussian input file" as *gif*. The saved file appeared as given in (Figure-9).

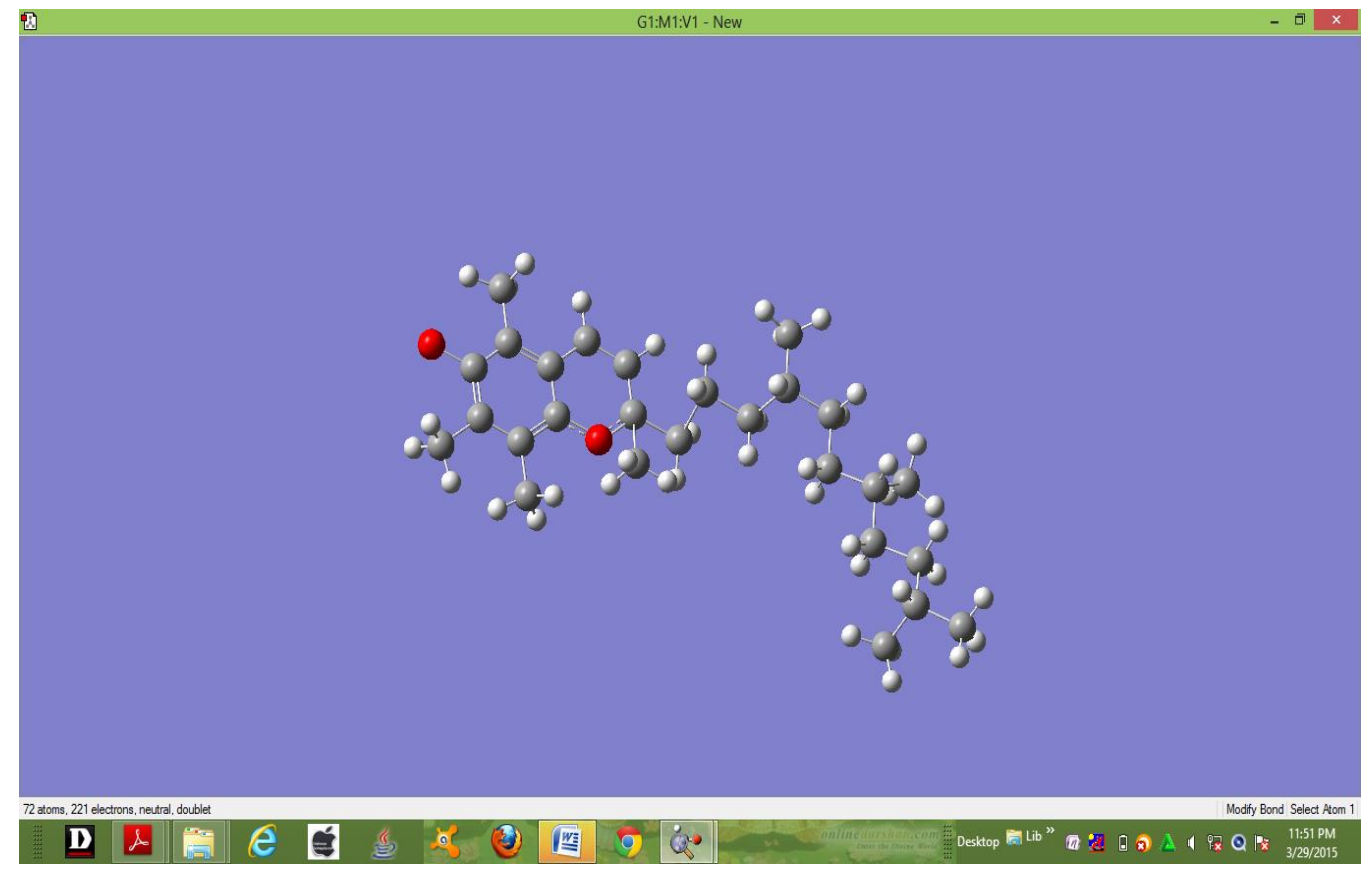

Figure 9. Gauss view of $\alpha$-tocopherol

- Click calculation option in the Gauss view main window menu then open the the Gaussian calculation setup window, which appear as given in (Figure-10). 


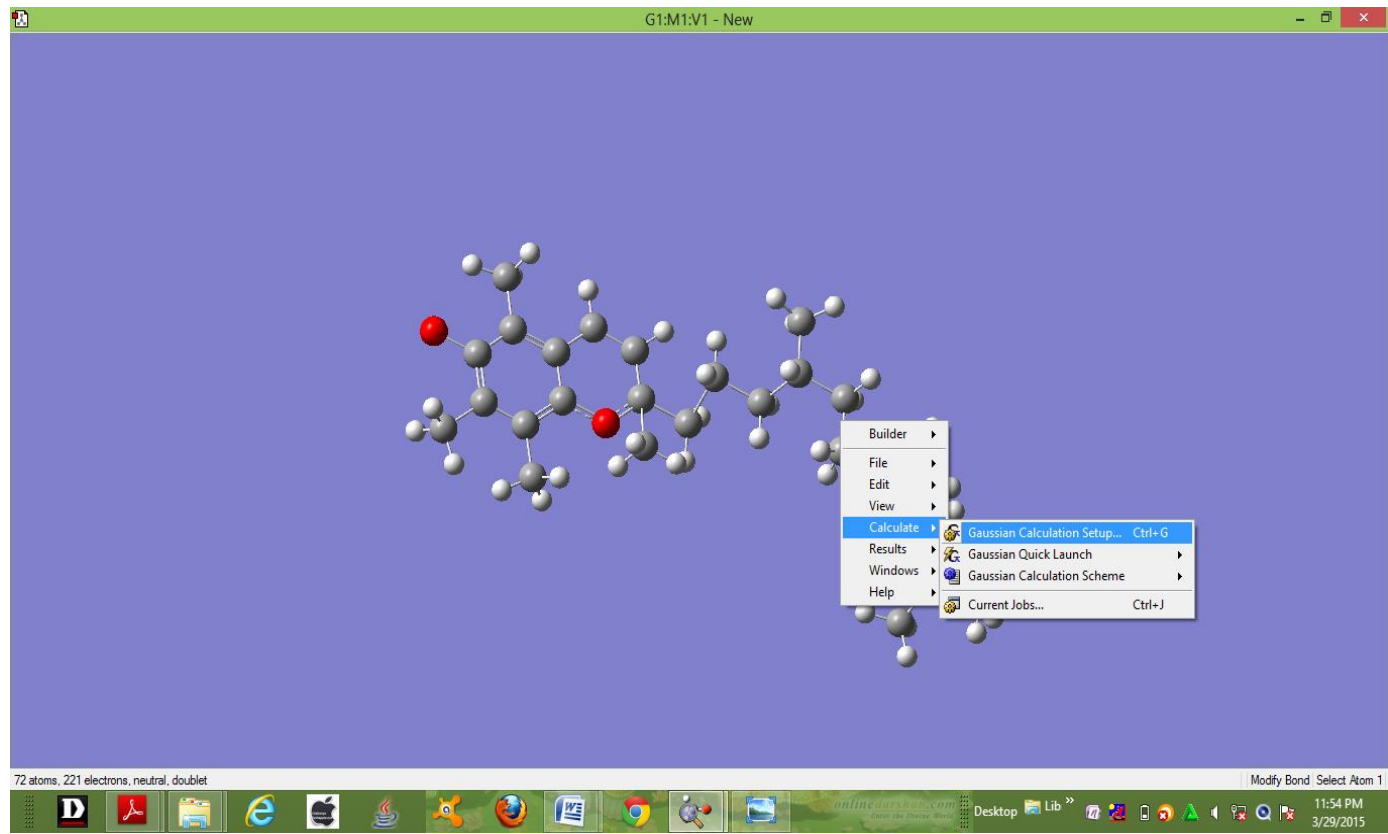

Figure 10. Calculation setup window

Under Job type, look at the various calculation options - like Optimization, frequency scan and energy calculations were used. Choose optimization to calculate the optimum geometry and the window looks like the window given as appeared as (Figure-11).

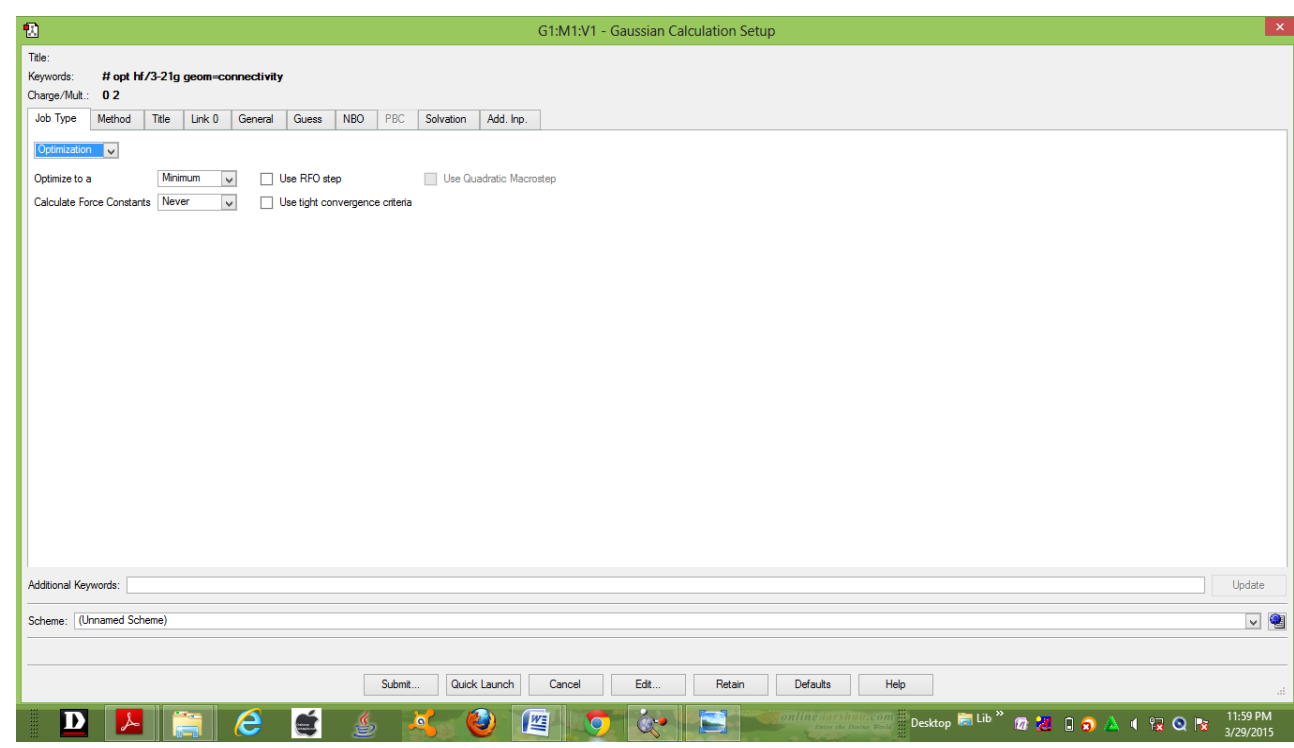

Figure 11. Optimization setup window

To calculate the binding energy by B3LYP, Select B3LYP and the corresponding basis set. The windows appear as given in (Figure-12). 


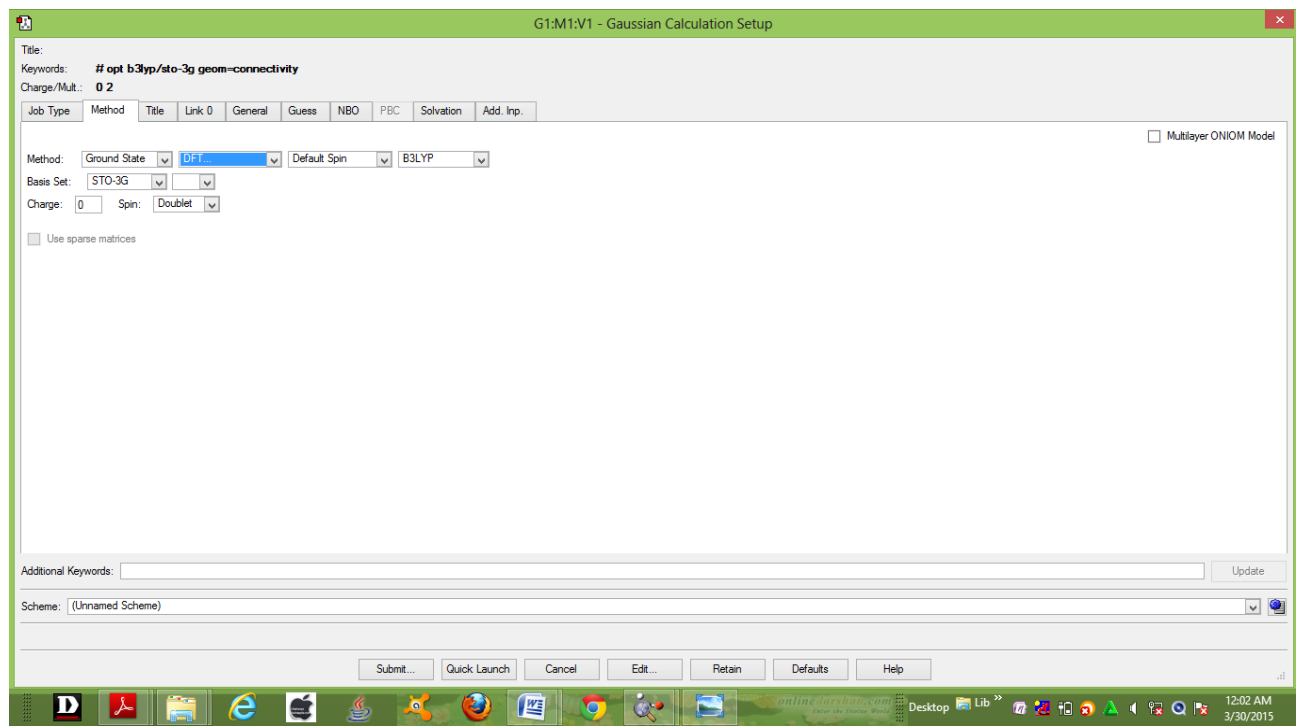

Figure 12. Energy calculation setup window in B3LYP method

On pressing submit button, it send the calculation from Gauss view to Gaussian. After finishing the calculation press "OK" to save the output file. The binding energy of the above six phytochemical compounds predicted by B3LYP method were given in Tables-II.

Table II. Binding energy of phytochemical compounds in B3LYP method

\begin{tabular}{|c|c|c|c|c|}
\hline \multirow[t]{2}{*}{ S.No } & \multirow[t]{2}{*}{ Compounds } & \multicolumn{3}{|l|}{ Basis Sets } \\
\hline & & STO-3G & 3-21G & $6-31 G$ \\
\hline 1 & Dodecanoic acid & -612.9438 & -617.5225 & -620.7334 \\
\hline 2 & Ethyl caprylate & -534.0572 & -538.2141 & -541.0285 \\
\hline 3 & $\begin{array}{l}\text { Glycine(trifluoroacetyl)-methyl butyl } \\
\text { ester }\end{array}$ & -916.3646 & -923.9007 & -928.7137 \\
\hline 4 & Capric acid ethyl ester & -604.5936 & -609.3381 & -612.6145 \\
\hline 5 & $\alpha$-Tocopherol & -1228.3913 & -1236.9904 & -1243.4557 \\
\hline 6 & n-Hexadecanoic acid & -769.2641 & -774.6944 & -778.7309 \\
\hline
\end{tabular}

To carry out energy calculation using an Abinitio Hartree -Fock model.

Select ground state, HF and set the basis set for 3-21G, the windows appear as (Figure-13). 
DOI: $10.21522 /$ TIJBMS.2016.02.02.Art002

ISSN: $2519-500 \mathrm{X}$

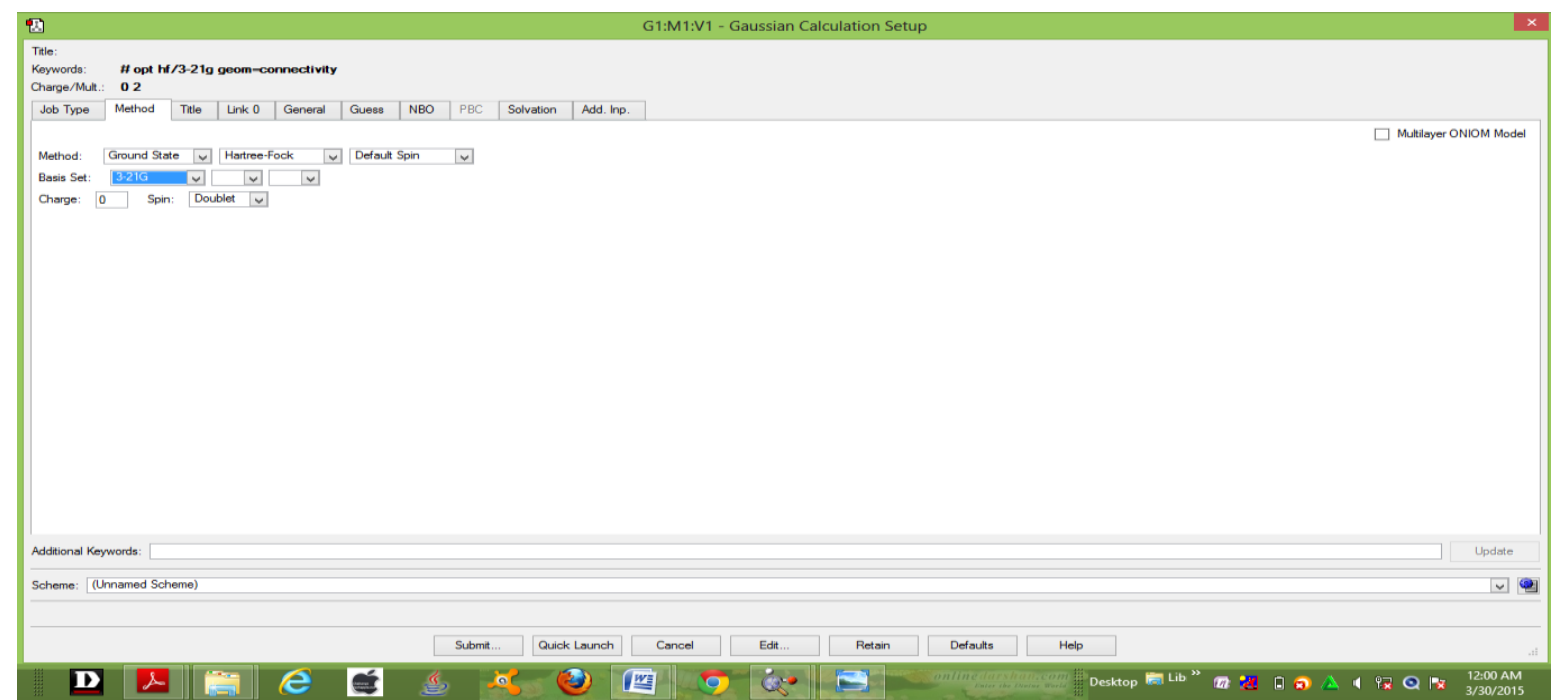

Figure 13. Energy calculation setup window in HF method

The binding energy of the above six phytochemical compounds were predicted by HF method was given in Table-III.

Table III. Binding energy of phytochemical compounds in HF method

\begin{tabular}{|l|l|l|l|l|}
\hline \multirow{2}{*}{ S.No } & Compounds & \multicolumn{2}{l|}{ Basis sets } \\
\cline { 3 - 5 } & & STO-3G & $\mathbf{3 - 2 1 G}$ & $\mathbf{6 - 3 1 G}$ \\
\hline 1 & Dodecanoic acid & -608.6248 & -613.1928 & -616.3251 \\
\hline 2 & Ethyl caprylate & -530.3398 & -534.3699 & -537.1198 \\
\hline 3 & $\begin{array}{l}\text { Glycine(trifluoroacetyl)- } \\
\text { methyl butyl ester }\end{array}$ & -911.4252 & -918.6482 & -923.3547 \\
\hline 4 & Capric acid ethyl ester & -600.4629 & -605.0965 & -608.3111 \\
\hline 5 & $\alpha-$ Tocopherol & -1220.2810 & -1228.4658 & -1234.8000 \\
\hline 6 & n-Hexadecanoic acid & -764.2778 & -769.4424 & -773.3822 \\
\hline
\end{tabular}

\section{Results and discussion}

\section{Molecular property and bio-activity scores}

\section{a) Molecular property of the phytochemical compounds}

Among the six phytochemical compounds selected for insilico drug activity prediction by molinspiration showed that compound 2 and 3 obeyed the Lipinski's rule of five and showed good drug likeness scores. MiLog P values of these compounds were found to be $<5$ (range 2.007 to 3.701) indicated their good permeability across the cell membrane.

All the phytochemical compounds were found to have TPSA well below 160Á2 (26.305 to 55.403), molecular weight $<500$, Number of hydrogen bond donors $<5$, hydrogen bond acceptors $<4$, number of rotatable flexible bonds $<5$ and $n$-violations 0 . These facts indicated that all the six phytoconstituents were found to have drug likeness property. 


\section{b) Bioactivity scores of the compounds}

The bioactivity scores of the six compounds observed were as follows:

\section{i) GPCR ligand}

$\alpha$-Tocopherol (0.25) compound was found to be highly bioactive towards GPCR ligands $(>0)$ and others were found to be moderately active $(<-5-0)$.

\section{ii) Ion channel modulator}

The Ion channel modulator property $\alpha$ - Tocopherol $(0.15)$ was higher $(>0)$ than other compounds $(<0)$.

\section{iii) Kinase inhibitor}

Kinase inhibitor activities of Dodecanoic acid (-0.75), Ethyl caprylate (-1.25), Glycine (trifluoroacetyl)-methyl butyl ester (-0.88), Capric acid ethyl ester (-0.21), $\alpha$-Tocopherol (-0.22) and nHexadecanoic acid (-0.33) were found to moderate as their scores values were found to be less than zero.

\section{iv) Nuclear receptor ligand}

Nuclear receptor ligand as the six compounds was observed to be moderate.

\section{v) Protease inhibitor}

$\alpha$ - Tocopherol was found to be active as Protease inhibitor $0.29(>0)$. Whereas other compounds were found to be moderately active $(<0)$.

\section{vi) Enzyme inhibitor}

$\alpha$-Tocopherol (0.25) and n-Hexadecanoic acid (0.18) were exhibited the enzyme inhibitory action higher $(>0)$ than other compounds $(<0)$. Among these two compound $\alpha$-Tocopherol the enzyme inhibitor activity was higher.

\section{IV - DFT Calculation}

\section{a) B3LYP method}

The binding energy calculation by using three basis sets (STO-3G, 3-21G, 6-31G) listed in Table-II showed the following result.

The binding energies for the Dodecanoic acid, Ethyl caprylate, Glycine (trifluoroacetyl) methyl butyl ester, Capric acid ethyl ester, $\alpha$ - Tocopherol and n-Hexadecanoic acid compounds using STO-3G basis were to be $-612.9438,-534.0572,-916.3646,-604.5936,-1228.3913$ and -769.2641 a.u. From the above data it was found that $\alpha$ - Tocopherol was found to have good binding energy as -1228.3913 a.u. among the other bio-active constituents. Using 3-21G basis sets, the binding energies were found to be 617.5225, -538.2141, -923.9007, -609.3381, - 1236.9904 and -774.6944 a.u. for the above compounds respectively. From these data it was found that $\alpha$-Tocopherol have a good binding energy as -1236.9904 a.u among the other bio-active constituents. The binding energies of the above six compounds by 6$31 \mathrm{G}$ basis sets were found to be $-620.7334,-541.0285,-928.7137,-612.6145,-1243.4557$ and 778.7309 a.u. From the above data it was concluded that $\alpha$-Tocopherol was found to have a good binding energy as -1243.4557 a.u. among the other bio-active constituents. It was observed that $\alpha$ Tocopherol was found to have $\mathbf{- 1 2 2 8 . 3 9 1 3 , - 1 2 3 6 . 9 9 0 4 , ~ - 1 2 4 3 . 4 5 5 7}$ a.u. binding energies as per the above three basis sets and hence it was found to be more stable than other bio-active constituents.

\section{b) HF method}

The binding energy calculation by HF method were listed in Table-III showed the following Observations. STO-3G basis sets, the binding energy for the selected six compounds were found $608.6248,-530.3398,-911.4252,-600.4629,-1220.2810$ and -764.2778 a.u. and it was found that $\alpha-$ Tocopherol (-1220.2810 a.u.) have good binding energy. 
Using 3-21G basis sets, the binding energies were found to be $-613.1928,-534.3699,-918.6482$, $605.0965,-1228.4658$ and -769.4424 a.u. for the six compounds. From these data, $\alpha$-Tocopherol (1228.4658 a.u.) was found to be more stable.

The binding energies observed using 6-31G basis sets for the above six compounds were found to $616.3251,-537.1198,-923.3547,-608.3111,-1234.8000$ and -773.3822 a.u. From these data it was found that $\alpha$ - Tocopherol (-1234.8000 a.u.) was found to be more stable among other compounds.

- Phytochemical compounds selected for our work (Figure- 1 to 6) were found to obey the Lipinski's rule (MiLog P <5) and $\alpha$ - Tocopherol (2.007) exhibited higher drug likeness properties compared to others. $\alpha$ - Tocopherol exhibited the highest score towards GPCR ligand, $(0.25)$ nuclear receptor ligand $(0.43)$ and inhibitory activities towards protease $(0.29)$, enzyme $(0.25)$ and kinase $(-0.22)$ inhibitors as higher compared to others.

- DFT method for determination of binding energy of the six phytoconstituent revealed that $\alpha$ Tocopherol was found to possesses good binding energy among others hence it was found to be more stable.

\section{Conclusion}

Phytochemical compounds selected for our work (Figure- 1 to 6) were found to obey the Lipinski's rule (MiLog P <5) and $\alpha$ - Tocopherol (2.007) exhibited higher drug likeness properties compared to others. $\alpha$ - Tocopherol exhibited the highest score towards GPCR ligand, $(0.25)$ nuclear receptor ligand $(0.43)$ and inhibitory activities towards protease $(0.29)$, enzyme $(0.25)$ and kinase $(-0.22)$ inhibitors as higher compared to others. DFT method for determination of binding energy of the six phytoconstituent revealed that $\alpha$-Tocopherol was found to possesses good binding energy among others hence it was found to be more stable.

\section{References}

[1]. Anastas, P.T. I.J. Levy, K.E. Parent (Eds). Green Chemistry Education. Changing the Course of Chemistry, ACS Publications, Washington DC, 2009.

[2]. Basu and Kirtikar. Indian Medicinal Plants. Vol. II, Second edition .International Book distributors Dehradun India, 867-868; 1935.

[3]. Diebold. U. The surface science of titanium dioxide. Sur Sci Rep, 48: 53-229; 2003. http://www.molinspiration.com.

[4]. Evans. W.C. Trease and Evans Pharmacognosy W.B. Saunders Company Ltd., London, pp (14th Edition). 19-20; 2000.

[5]. Grossman. E. Chasing Molecules: Poisonous Products, Human Health, and the Promise of Green Chemistry. Island Press, New York, 2009.

[6]. Lipinski, C.A. F. Lombardo, B.W. Dominy, P.J. Feeney. Adv Drug Delivery Rev., 23(1-3):3-25; 1997.

[7]. Lipinski, C.A. F. Lombardo, B.W. Dominy, P.J. Feeney. Adv Drug Deliv Rev; 46 (1-3): 3-26; 2001.

[8]. Lipinski. C.A. Drug Discovery Today: Technologies; 1 (4): 337-34; 2004.

[9]. Mossi, Mazutti, A.J. M. Paroul, N. Corazza, M.L. Dariva, C. Cansian \& R.L. Oliveira, O.R. Rocha, R.F. Dantas, M.M.M.B. Duarte, et al. Oil sludge treatment by photocatalysis applying black and white light. Chem Eng J, 157: 80-85; 2010.

[10]. Mukunthan, K.S. E.K. Elumalai, N.P. Trupti, V. Ramachandra Murty. Catharanthus roseus: a natural source for the synthesis of silver nanoparticles. Asian Pacific Journal of Tropical Biomedicine, 270-274; 2011.

[11]. Newman, D.J. G.M. Cragg, K.M. Snadder. J. Nat. Prod., 66(7): 1022 -1037; 2003.

[12]. Prakash. S.K. Int. J. Poultry Sci. 5: 259-261; 2006.

[13]. Sharma. S.K. Green Chemistry for Environmental Sustainability. Series: Advancing Sustainability Through Green Chemistry and Engineering. CRC Press, Boca Raton, FL, 2010.

[14]. Thirumurgan, A. N.A. Tomy, R. Jai Ganesh, S. Gobikrishnan. Biological reduction of silver nanoparticles using plant leaf extracts and its effect an increased antimicrobial activity against clinically isolated organism. De. Phar. Chem, 2: 279-284; 2010.

[15]. Tripathy, A. A.M. Raichur, N. Chandrasekaran, T.C. Prathna, A. Mukherjee. J. Nanopart. Res.12, 237; 2010.

DOI: $10.1007 / \mathrm{s} 11051-009-9602-5$

[16]. Tagboto, S. S. Townson. Adv. Parasitol., 50: 199-295; 2001. 
Texila International Journal of Basic Medical Science Volume 2, Issue 2, Dec 2017

[17]. Thompson, T.L. J.T. Yates Jr. Surface science studies of the photoactivation of TiO2-New photochemical processes. Chem Rev, 106: 4428-4453; 2006. 